\title{
High-dose interleukin-2 (hd-IL2) in treatment-naïve metastatic renal cell carcinoma (mrcc) - a 10 year single-site experience and outcome of prospective pathology-based patient selection
}

\author{
Shien Chow ${ }^{1}$, Manon Evans ${ }^{1 *}$, Victoria Galvis ${ }^{1}$, Rebecca Leach', Elizabeth Keene ${ }^{1}$, Kevin Chan ${ }^{1}$, \\ Andrea Spencer-Shaw', Shanks Jonathan ${ }^{2}$, Alaaeldin Shabalak', Fiona Thistlethwaite', Robert Hawkins ${ }^{1}$
}

From Society for Immunotherapy of Cancer 29th Annual Meeting

National Harbor, MD, USA. 6-9 November 2014

\section{Background}

Despite the advent of targeted therapies, mRCC remains difficult to treat with limited prospect of cure. HD-IL2 is the only agent consistently capable of achieving durable long-term remissions. Shablak et al have previously reported improved outcomes in patients prospectively stratified by a pathology-based criterion compared to an unselected population. We now present updated outcomes of mRCC patients given first-line treatment with HD-IL2 over a 10 year period from July 2003 to July 2013.

\section{Methods}

The sample population consisted of 2 Cohorts: Cohort A (treated July 2003 - August 2006) where patients were retrospectively stratified for analysis by pathology into 'Favourable' and 'Other' groups ('Favourable' $=<10 \%$ papillary features, and at least 1 of $>50 \%$ alveolar/solid, or $>50 \%$ clear cell features); and Cohort B (treated August 2006 - July 2013) where patients were prospectively stratified. HD-IL2 was administered as per standard dosing and schedule. Clinical records were reviewed retrospectively; survivals were analysed by Kaplan-Meir methods. Carbonic Anhydrase 9 positivity $(\mathrm{CAIX}+)$ by immunohistochemistry was reviewed and recorded but was not used as selection criterion.

\section{Results}

145 patients were included in the analysis. Median age 56, $72.6 \%$ male gender. Overall, $87.6 \%$ and $12.4 \%$ of patients

'Department of Medical Oncology, Christie NHS Foundation Trust, Manchester, Manchester, United Kingdom

Full list of author information is available at the end of the article had 'Favourable' and 'Other' pathology type respectively. Outcomes in patients with 'Favourable' histology were consistent across all time periods with overall response rates (ORR) and complete response (CR) rate being $41 \%, 24 \% ; 48 \%, 23 \% ; 47 \%, 23 \%$ respectively in Cohort A, Cohort B and the total cohort.

Median overall survival (OS) of the total cohort was 55 months. Median OS for the HD-IL2 induced CR patients is not yet reached with $90 \%$ remaining alive and disease-free. A further 7 patients with 'Favourable' pathology achieved CR following surgical resection of residual disease with 4 currently alive and disease-free. Those with 'Other' pathology clearly responded less well.

We observed a high response rate (ORR 48\%, CR 26\%) in patients with CAIX $+>60 \% .5$ additional patients achieving CR were captured by lowering CAIX threshold from $80 \%$ to $60 \%$ positivity.

\section{Conclusions}

Our study confirms that HD-IL2 remains an effective firstline treatment in well-selected patients with mRCC, emphasising further the sustained responses and longterm survival of those achieving a CR. Prospective application of our pathology-based selection criterion continues to correlate significantly with improved ORR and CR rates. CAIX appears predictive of response even at $60 \%$ ( $80 \%$ previously reported as significant), but should be analysed further prior to being considered as a selection adjunct. 


\section{Authors' details}

'Department of Medical Oncology, Christie NHS Foundation Trust,

Manchester, Manchester, United Kingdom. ${ }^{2}$ Department of Histopathology,

Christie NHS Foundation Trust, Manchester, United Kingdom.

Published: 6 November 2014

doi:10.1186/2051-1426-2-S3-P89

Cite this article as: Chow et al: High-dose interleukin-2 (hd-IL2) in

treatment-naïve metastatic renal cell carcinoma (mrcc) - a 10 year single-

site experience and outcome of prospective pathology-based patient

selection. Journal for ImmunoTherapy of Cancer 2014 2(Suppl 3):P89.

Submit your next manuscript to BioMed Central and take full advantage of:

- Convenient online submission

- Thorough peer review

- No space constraints or color figure charges

- Immediate publication on acceptance

- Inclusion in PubMed, CAS, Scopus and Google Scholar

- Research which is freely available for redistribution

Submit your manuscript at www.biomedcentral.com/submit 